\title{
Article \\ Self-Healing Potential and Post-Cracking Tensile Behavior of Polypropylene Fiber-Reinforced Cementitious Composites
}

\author{
Mohit Garg ${ }^{1}$ (D) Pejman Azarsa ${ }^{1}$ (D) and Rishi Gupta ${ }^{2, *(D)}$ \\ 1 Facility for Innovative Materials and Infrastructure Monitoring (FIMIM), Department of Civil Engineering, \\ University of Victoria, Victoria, BC V8P 5C2, Canada; mgarg@uvic.ca (M.G.); pazarsa@uvic.ca (P.A.) \\ 2 Department of Civil Engineering, University of Victoria, Victoria, BC V8P 5C2, Canada \\ * Correspondence: guptar@uvic.ca
}

check for updates

Citation: Garg, M.; Azarsa, P.; Gupta, R. Self-Healing Potential and Post-Cracking Tensile Behavior of Polypropylene Fiber-Reinforced Cementitious Composites. J. Compos. Sci. 2021, 5, 122. https://doi.org/ $10.3390 /$ jcs5050122

Academic Editor: Jian-Guo Dai

Received: 12 April 2021

Accepted: 30 April 2021

Published: 7 May 2021

Publisher's Note: MDPI stays neutral with regard to jurisdictional claims in published maps and institutional affiliations.

Copyright: (c) 2021 by the authors. Licensee MDPI, Basel, Switzerland. This article is an open access article distributed under the terms and conditions of the Creative Commons Attribution (CC BY) license (https:// creativecommons.org/licenses/by/ $4.0 /)$.

\begin{abstract}
The use of synthetic fibers as reinforcement in fiber-reinforced cementitious composites (FRCC) demonstrates a combination of better ductile response vis-à-vis metallic ones, enhanced durability in a high $\mathrm{pH}$ environment, and resistance to corrosion as well as self-healing capabilities. This study explores the effect of macro- and micro-scale polypropylene (PP) fibers on post-crack energy, ductility, and the self-healing potential of FRCC. Laboratory results indicate a significant change in fracture response, i.e., loss in ductility as curing time increases. PP fiber samples cured for 2 days demonstrated ductile fracture behavior, controllable crack growth during tensile testing, postcracking behavior, and a regain in strength owing to FRCC's self-healing mechanism. Different mixes of FRCC suggest an economical mixing methodology, where the strong bond between the PP fibers and cementitious matrix plays a key role in improving the tensile strength of the mortar. Additionally, the micro PP fiber samples demonstrate resistance to micro-crack propagation, observed as an increase in peak load value and shape deformation during compression and tensile tests. Notably, low volume fraction of macro-scale PP fibers in FRCC revealed higher post-crack energy than the higher dosage of micro-scale PP fibers. Lastly, few samples with a crack of $<0.5 \mathrm{~mm}$ exhibited a self-healing mechanism, and upon testing, the healed specimens illustrated higher strain values.
\end{abstract}

Keywords: fiber-reinforced cementitious composites (FRCC); self-healing (SH); polypropylene fiber; tensile strength; concrete cracking

\section{Introduction}

Cement-based composites are typically quasi-brittle materials in nature with several well-known benefits, including easy forming, low cost, local availability, and a fairly sustainable character [1,2]. Opposing these main advantages, non-beneficial properties of cement-based materials, such as low tensile strengths (around one tenth of their corresponding compressive strength), low strain capacity, low ductility, and poor resistance to crack opening and propagation, could result in several combined complex issues related to their structural integrity, load-carrying capacity, and durability properties. This can ultimately lead to a decrease in the material's serviceability and raise the essential needs to maintain, repair, and monitor these cement-based materials on a routine basis. As an example, annually, half of the budget for UK construction work (about $£ 80 \times 10^{9}$ ) is dispensed to the rehabilitation and maintenance of existing structures [3]. Such annual expenditure in the industrialized world points toward the crucial need to develop more durable and sustainable cementitious materials.

The structural performance and durability of cementitious materials is basically compromised by the induction of cracks developed at an early age by plastic shrinkage, or a later age by tensile/flexural loadings, thermal stresses, or reinforcement corrosion. These cracks create potential pathways for deleterious agents (e.g., chloride ions, acid rain, or carbon dioxide) that can penetrate inside the composite's matrix, and thus can reduce its durability and strength. Although cracking may not be avoidable at any point in the 
service life of a structure, the great inherent capacity of cement-based materials in healing these cracks makes them strongly valuable materials for the construction industry. This time-dependent phenomenon is called "Self-healing (SH)". Crack healing phenomena in autogenous mode can largely occur inside cement-based materials through four mechanisms, including (1) the formation of calcite (mostly known as calcium carbonate, $\mathrm{CaCO}_{3}$ ), (2) ongoing hydration upon moisture contact, (3) swelling of the cementitious matrix, and (4) the sedimentation of debris/particles [4]. SH eventually results in recovering certain mechanical or durability properties of the cement paste. During the past two decades, numerous research studies have been performed to establish the different characteristics of natural healing in cement-based materials [5-18]. Intrinsic SH has limited applications because of its limited crack-closing capability $(\sim 200-300 \mu \mathrm{m})$ and the conditional occurring of this phenomenon $[7,16,19-21]$. Hence, several researchers and engineers put efforts toward initiation and development of various innovative techniques to manufacture and produce new conceptual engineered self-healing cementitious composites (EShCC) [22]. Artificially, these composites can be triggered by healing agents such as bacteria microencapsulation or crystalline admixtures, which results in crack closure and strength recovery. Beneficial aspects of using EShCC, such as in situ self-repair or an increase in ultimate service life, make it a significantly interesting topic in the construction world [3,7,22-47].

One of the methodologies for fabrication of EShCC is the addition of discontinuous and randomly dispersed fibers that can control formation and limit the growth of cracks inside the matrix due to the bridging effects provided by fibers. They also provide enough support and time for any type of $\mathrm{SH}$ mechanisms to occur. Other advantages of fiber additions are tensile/flexural strength enhancement and the improvement of ductility and toughness (in terms of absorbed strain energy) [48]. Considering the crack restraining capability and the gain in strain capacity of fiber-reinforced cementitious composites (FRCC), it can additionally act as a reliable option for seismic applications [49]. The absence of coarse aggregates (only presence of fine aggregate) in FRCC can improve the composite's fracture toughness but can decrease its elastic modulus [50]. Although FRCC's mechanical properties can be significantly ameliorated by the addition of contemporary short fibers, such as carbon, steel, 3D-printed, and glass fibers, these fibers, once added, cannot establish noticeable ductile behavior [51-53]. Hence, to mitigate FRCC's brittle behavior, synthetic fibers have been integrated into the base mix, and the resulting FRCC demonstrated higher ductility. The authors believe that these fibers may also prove helpful in the crack indication process for $\mathrm{SH}$ investigation. As compared to metallic fibers, the durability of synthetic fibers does not reduce by the corrosion process [54]. Among these synthetic fibers, polypropylene (PP) fibers are popular for reinforcing cementitious composites and have attracted the most attention among researchers due to its relatively low cost and weight, being inert in a high $\mathrm{pH}$ environment, resistance to corrosion and shrinkage cracking, easy dispersion process, high melting point, and chemical stability [55-58]. As described above, the studies have shown that the inclusion of fibers results in enhancement of post-cracking behavior as well as less brittle behavior. However, over the past few years, the usability of PP fibers in FRCC to enhance their post-cracking behavior has caught the attention of many researchers.

\section{Novelty of the Study}

From the literature review, it was evident to the authors that the influence of fiber volume content, geometry, orientation, length, etc., on post-cracking and $\mathrm{SH}$ behavior of FRCC when cured under different regimes, is not well understood and is scarcely available in the literature. A recent study conducted by the authors [41] indicated that the inclusion of PP fiber in virgin concrete resulted in a higher SH ratio and higher dynamic modulus of elasticity. The enhancement was detected by a resonance frequency testing method, but several knowledge gaps remained. This paper attempts to close the gap between the current research and industry knowledge on post-cracking tensile and SH properties 
of FRCC specimens reinforced with macro or micro PP fibers when exposed to various environmental conditions.

This is the first known study that has focused on studying the combined effect of polypropylene fiber-reinforced cement composites (PFRCC) on post-cracking behavior, ductility, crack-closing, and self-healing potential of dog-bone-shaped briquettes subjected to tensile loading. The use of PFRCC with a crack controlling capability and high compressive strain capacity can mitigate damage, increase ductility, and potentially increase the crack healing capacity. Changes in compressive strength, tensile strength, ductile behavior, crack width, and its healing potential were measured relative to the reference samples. This study significantly contributes towards a better understanding of these important mechanical and self-healing properties of PFRCC.

\section{Materials and Methods}

This section explains the methods utilized for the preparation and storage of the PFRCC samples, as well as the techniques used for inducing cracks in the specimens and determining the compressive and tensile strengths.

In compliance with CSA A23.1 standard, Portland cement type GU, with properties similar to ASTM C150-Type I cement, was utilized for all batches. In accordance with the ASTM C 33 criteria, natural river sand was selected as fine aggregates. The specific gravity, water absorption, and fineness of fine aggregates used in this study were $2.7,1.2 \%$, and 2.6, respectively. Two commercially available polypropylene (PP) fibers were used for this research study. El-Newihy et al. [41] describes them as Type A and B. The former type is a macro monofilament fiber with a patented sinusoidal deformation, while the latter is a $100 \%$ smooth virgin polypropylene micro fiber. Further, El-Newihy et al. [41] presented different properties of PP fibers (also used for the present study), as summarized in Table 1 below. Type A-macro PP fiber and Type B-micro PP fiber are shown in Figure 1. Types $A$ and $B$ from here on in this study refer to designations for the macro and micro fibers, respectively. In addition, Master-Pozzolith 210 provided by BASF ${ }^{\circledR}$ was used as a water reducing admixture (WRA) for mixtures. WRA was added at a dosage of $1.832 \mathrm{~kg} / \mathrm{m}^{3}$ to maintain the workability when adding fibers.

Table 1. Polypropylene fiber properties [41].

\begin{tabular}{cccc}
\hline Mechanical Property & Unit & Type A-PP Macro Fiber & Type B-PP Micro Fiber \\
\hline Fiber Length & $\mathrm{mm}$ & 50 & 12 \\
Equivalent Diameter & $\mathrm{mm}$ & 0.5 & 0.018 \\
Specific Gravity & - & 0.91 & 0.9 \\
Aspect Ratio & $\%$ & 0.5 & 0.5 \\
Elastic Modulus & $\mathrm{GPa}$ & 7.5 & 7 \\
Tensile Strength & $\mathrm{MPa}$ & 550 & $300-450$ \\
Water Absorption & $\%$ & 0 & 0 \\
Melting Point & ${ }^{\circ} \mathrm{C}$ & 164 & 162 \\
Thermal & $\mathrm{W} / \mathrm{mK}$ & Low & N/A \\
Conductivity & $\mathrm{Kg} / \mathrm{m}^{3}$ & 910 & 900 \\
Density & & &
\end{tabular}

\subsection{Mixture Proportioning}

As summarized in Table 2, PFRCC compositions and mixture proportions were calculated according to ACI 211.1. A total of 9 mixes were prepared as detailed in Table 2. The authors chose different dosages of the fibers in order to consider a wide range but also used what is commonly specified by the manufacturer. The amount of cement content, fine aggregates, and WRA were kept constant in all mixes. The water to binder $(w / b)$ ratio employed was 0.45 for all PFRCC mixes and the control mix. This $\mathrm{w} / \mathrm{b}$ was chosen to attain a target compressive strength of 25-30 MPa. 


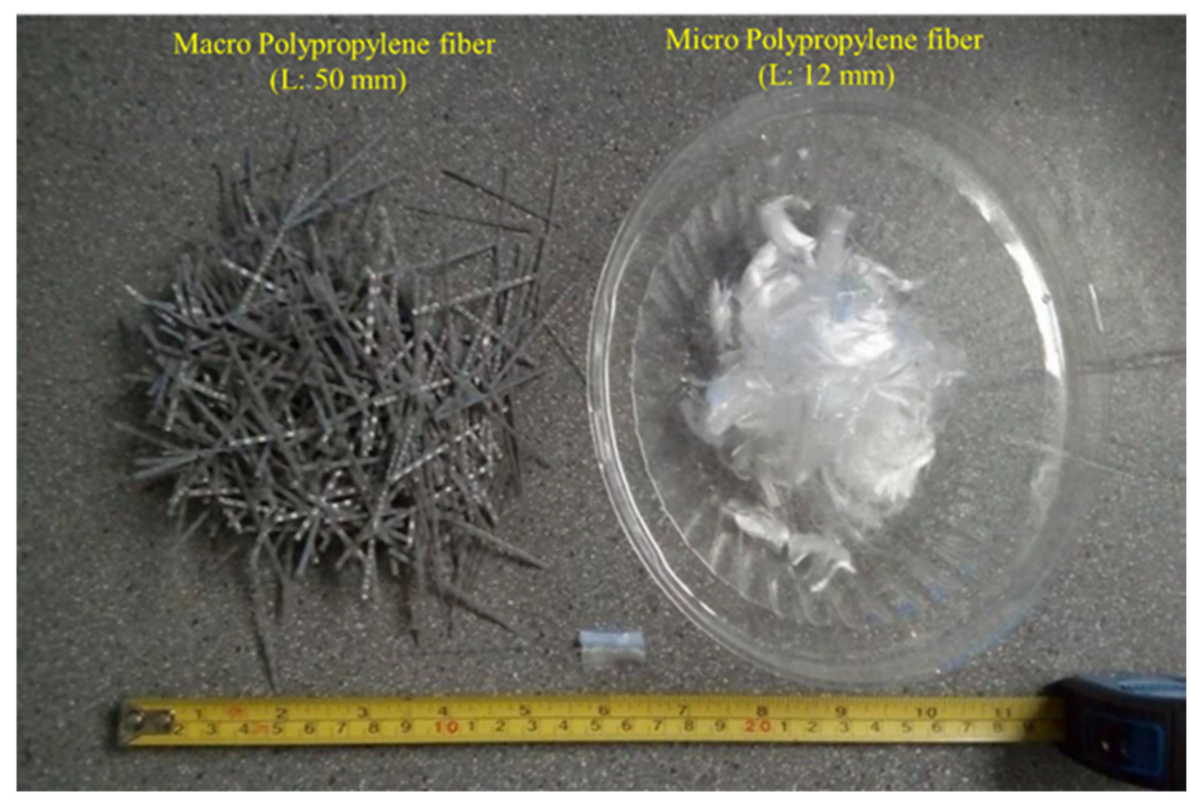

Figure 1. Macro (left) and micro (right) polypropylene fibers [41].

Table 2. Fiber dosages in mixer.

\begin{tabular}{|c|c|c|c|c|}
\hline \multirow{2}{*}{ No. } & \multirow{2}{*}{ Mixture ID } & \multirow{2}{*}{ Fiber Type } & \multicolumn{2}{|c|}{ Fiber Dosage } \\
\hline & & & $\%$ By Volume & $\left(\mathrm{kg} / \mathrm{m}^{3}\right)$ \\
\hline 1 & Plain & - & - & - \\
\hline 2 & PP0.3 & PP & 0.3 & 2.7 \\
\hline 3 & PP0.6 & PP & 0.6 & 5.4 \\
\hline 4 & PP0.75 & PP & 0.75 & 6.75 \\
\hline 5 & PP1.0 & PP & 1.0 & 9.00 \\
\hline 6 & PP1.25 & PP & 1.25 & 11.25 \\
\hline 7 & PP2.0 & PP & 2.0 & 18.0 \\
\hline 8 & МРP0.3 & MPP & 0.3 & 2.73 \\
\hline 9 & МРP0.6 & MPP & 0.6 & 5.46 \\
\hline 10 & MPP1.25 & MPP & 1.25 & 11.38 \\
\hline
\end{tabular}

\subsection{Specimen Preparation and Curing Conditions}

Following the procedures reported in ASTM C192 [59], dog-bone-shaped PFRCC specimens with a length of $76.2 \mathrm{~mm}$, a maximum width of $44.45 \mathrm{~mm}$, and a depth of $25 \mathrm{~mm}$ were cast (a total of 15 samples) for measuring tensile strength. Three dog-bone-shaped samples were used for each of the following scenarios: prior to cracking, post crack, and healed crack to measure the effect on tensile strength. The average of the 3 samples for each scenario is reported in this study. With the same mix, authors also casted $50 \mathrm{~mm}$ cubic PFRCC specimens (a total of 3 for each mix) for measuring compressive strength, as shown in Figure 2. In general, authors observed reduced workability as more PP fibers were added to the cementitious mixture. However, in only certain cases extra water was added to maintain the same workability. Such details are added in the appropriate section of this study. Promptly after the casting of PFRCC samples, they were sealed with a plastic sheet to maintain the moisture inside the specimens for $24 \mathrm{~h}$ at the laboratory environment (room temperature). After $24 \mathrm{~h}$ and prior to testing, samples were left to dry in air, and then tested according to the curing schedule (details in Section 3) for each sample. 


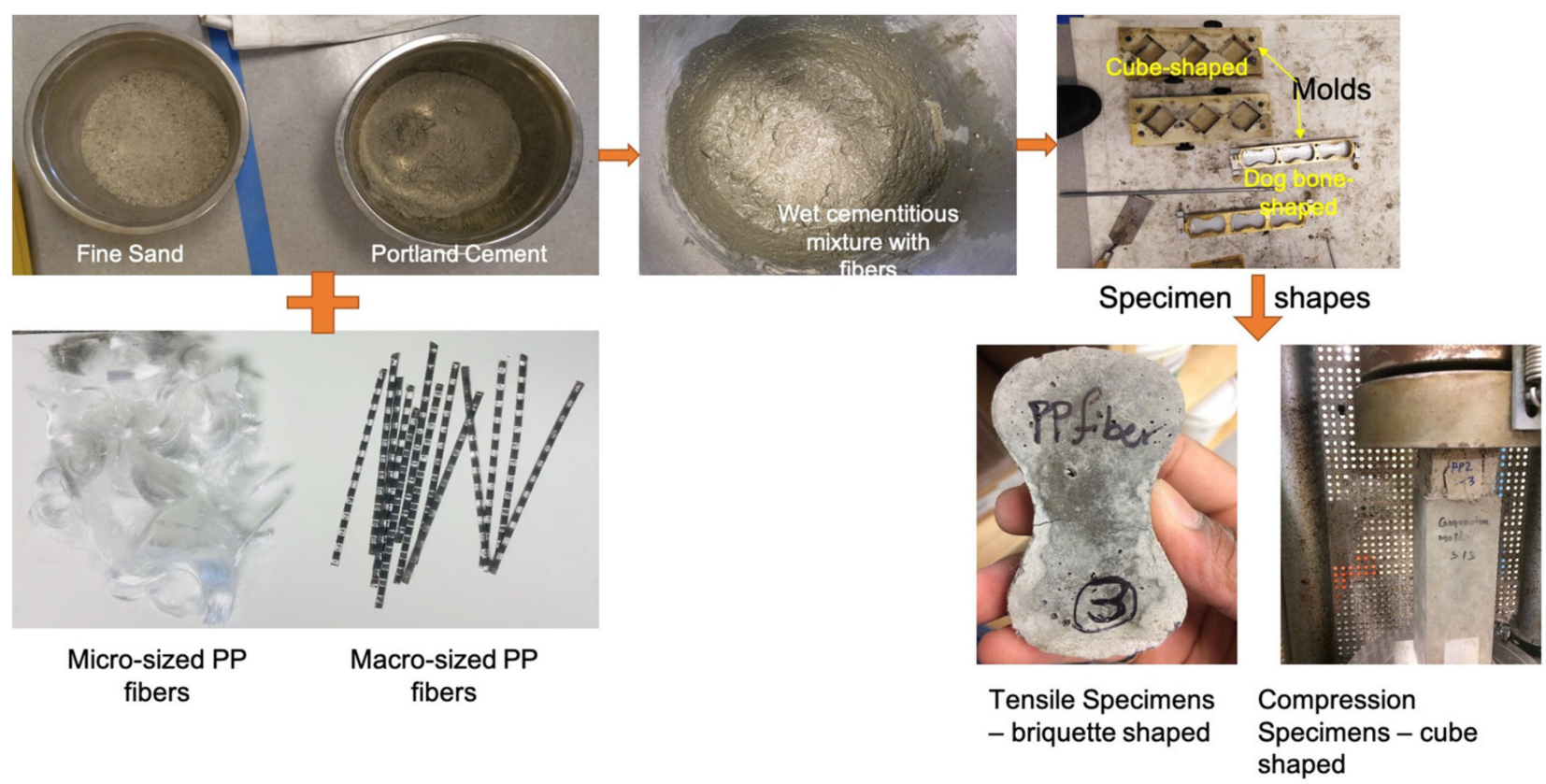

Figure 2. Mixing procedure to prepare PFRCC samples.

\subsection{Testing}

\subsubsection{Mechanical Properties}

Compressive Strength

The focus of the current study was on the mortar phase. Hence, the authors chose to evaluate the compressive strength mix using cube-shaped samples as per ASTM C109 [60]. Through this study, $50 \mathrm{~mm}$ cubical specimens were examined according to ASTM C109 standard [60]. A Forney compression machine was used in this work, which had a maximum capacity of $3000 \mathrm{KN}$ with an applied loading rate maintained at $0.25 \pm 1 \mathrm{MPa} / \mathrm{s}$ for every test. For each mix, an average of 3 PFRCC cubes were tested in saturated surface dry (SSD) conditions.

\section{Tensile Strength}

In this study, dog-bone (briquette-shaped) specimens were examined according to ASTM C307 standard [61]. Brass molds were prepared by referring to dimensions re-ported in Figure 3. A uniaxial tensile testing machine (MTM) was used that had a maximum capacity of $7100 \mathrm{~N}$ with an applied loading rate maintained at $0.48 \mathrm{~mm} / \mathrm{min}$ for every test as described in ASTM C307 [61]. Ultimate load, maximum deformation, and tensile strength were noted down for each type of specimen; the average of the three is reported for discussion and analysis.

\subsubsection{Investigation of Self-Healing and Crack-Closing Capability}

To induce cracks with similar characteristics in different specimens, the authors found from a parallel study that the ideal time to induce cracks was between 1-4 days of wet curing. This is mainly due to the fact that at an earlier age (e.g., 1 day of curing), the composite fractures in a ductile behavior, while at later ages (e.g., 28 days of curing), the failure occurs in a brittle manner. Different curing regimes in this study were also considered to understand the behavior of PFRCC during the crack induction process and to find the optimal curing period to generate a uniform crack width. To be consistent and to induce a constant crack width, the applied uniaxial tensile load under the MTM machine was terminated as soon as the dog-bone PFRCC sample cracked. The induced surface crack's width was later measured from each casting face of the briquette using an optical crack detection microscope at 8 equidistant points along the crack: 4 along 
the top face (finished surface) and 4 along the bottom face. These readings were then averaged and recorded as the specimen's average crack width. Changes in crack width was monitored after the healing time elapsed using the same microscope to identify the crackclosing capability and healing potential of these cementitious materials when PP fibers were added. After defined healing periods, specimens were tested under tension using the MTM machine to observe strength recovery and examine their ductility in comparison with prior- and post-cracking scenarios. The effect of curing conditions on tensile strength recovery and ductility behavior of PFRCC was also identified in a similar way. The crack location in a sample while it was being loaded under tensile conditions is illustrated in Figure 4 .

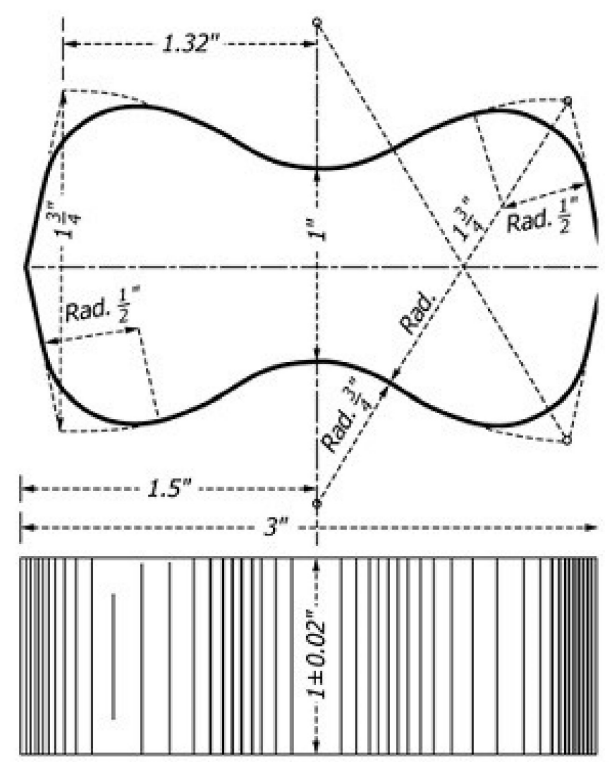

Figure 3. Dog-bone specimen dimensions for tensile strength test [61].

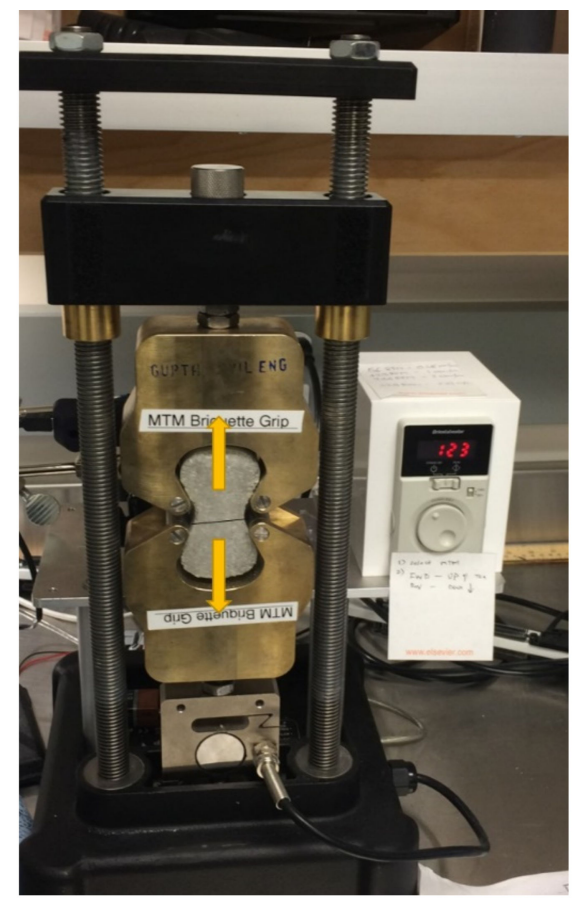

Figure 4. Cracked specimen when loaded in uniaxial tension. 


\section{Results and Discussion}

\subsection{Uniaxial Tensile Strength}

The tensile strength of concrete material is an equally important characteristic as its compressive strength. The tensile strength of the PFRCC material was measured by applying tensile load to the dog-bone-shaped specimens (briquette) until their failure in accordance with ASTM C307 [61]. The average ultimate tensile strength (UTS) obtained from tensile tests of PFRCC mortar samples after $24 \mathrm{~h}$ of water curing and with increasing dosages of PP fibers (0.3-2.0 vol\% of cement) is shown in Figure 5.

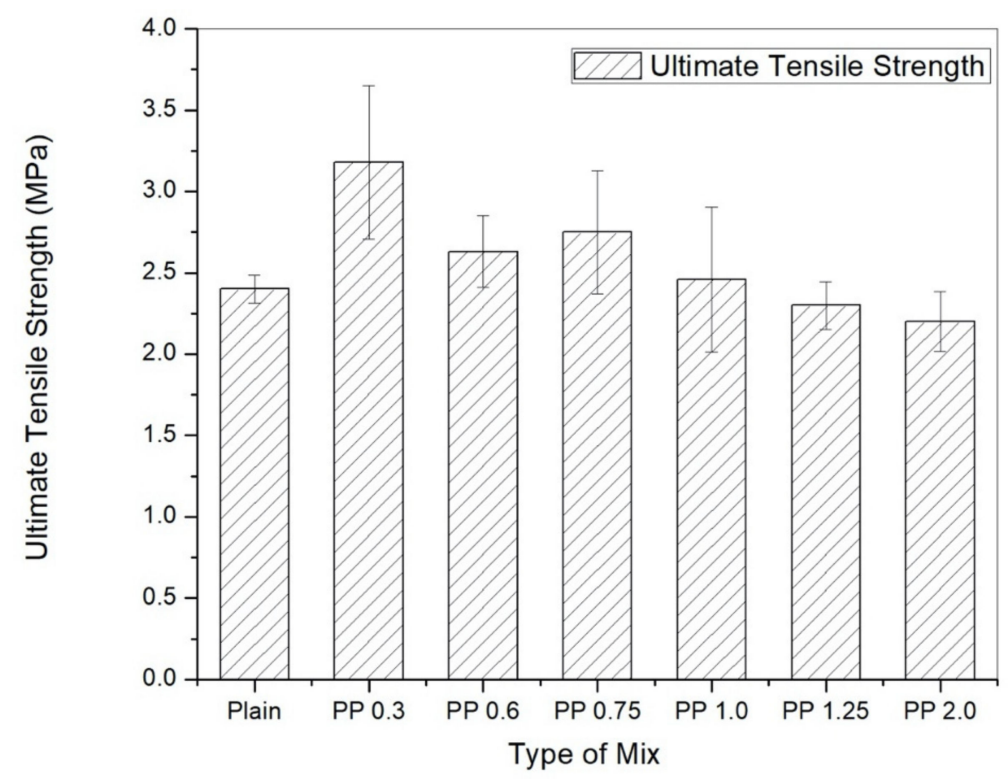

Figure 5. UTS of PFRCC with varying PP fiber dosage, $24 \mathrm{~h}$ curing.

The mortar samples with $0.3 \%$ and $0.75 \%$ volume fraction when compared to the control demonstrated considerable improvement in tensile strength with a $33 \%$ and $15 \%$ increase, respectively. It was observed that at a low volume, the effect of polypropylene fibers on tensile strength was not detrimental. Generally, the improvement in tensile strength of the FRCC is attributed to the ability of fibers to restrain and delay crack propagation as the load transfers from the matrix to the fibers. On the other hand, comparing the results of PFRCC with that of the control specimen indicates that the use of high fiber volume fraction results in a decrease in the tensile strength, possibly owing to fiber clumping and increased porosity in the fiber-matrix interface. These results nullify the hypothesis that an increasing volume fraction of PP fibers would allow the mortar to gain more strength. In addition to the above stated reasons, and to keep the manufacturing cost of PFRCC low for industrial application, $2.0 \mathrm{vol} \%$ was excluded from further investigation.

\subsubsection{Curing Duration and Temperature}

In general, curing duration and temperature have a strong influence on the hardening of cement products (both mortar and concrete) reflected in the mechanical properties and durability. According to ACI, concrete attains $70 \%$ of the specified compressive strength in seven days, and the rest is attained within 28 days. Moreover, if curing is performed in a suitable environment, at early stages of cement hydration, good concrete and mortar can be manufactured in a laboratory setting. In order to explore the effect of increasing curing time on the strength gained by the PFRCC, mortar samples with 0.3, 0.75, and $1.0 \mathrm{vol} \%$ PP were all initially cured in water for 5 days, and then left for an additional curing duration of up to 14 days or 28 days in accordance with ASTM C192 [59]. On the other hand, to compare the effects of air curing (AC) and water curing (WC), three samples of each volume fraction were left in air-dry conditions, i.e., after the initial 5-day wet curing. 
The UTS was recorded for the samples tested for distinctive curing conditions, and the average of the three samples is shown in Figure 6.

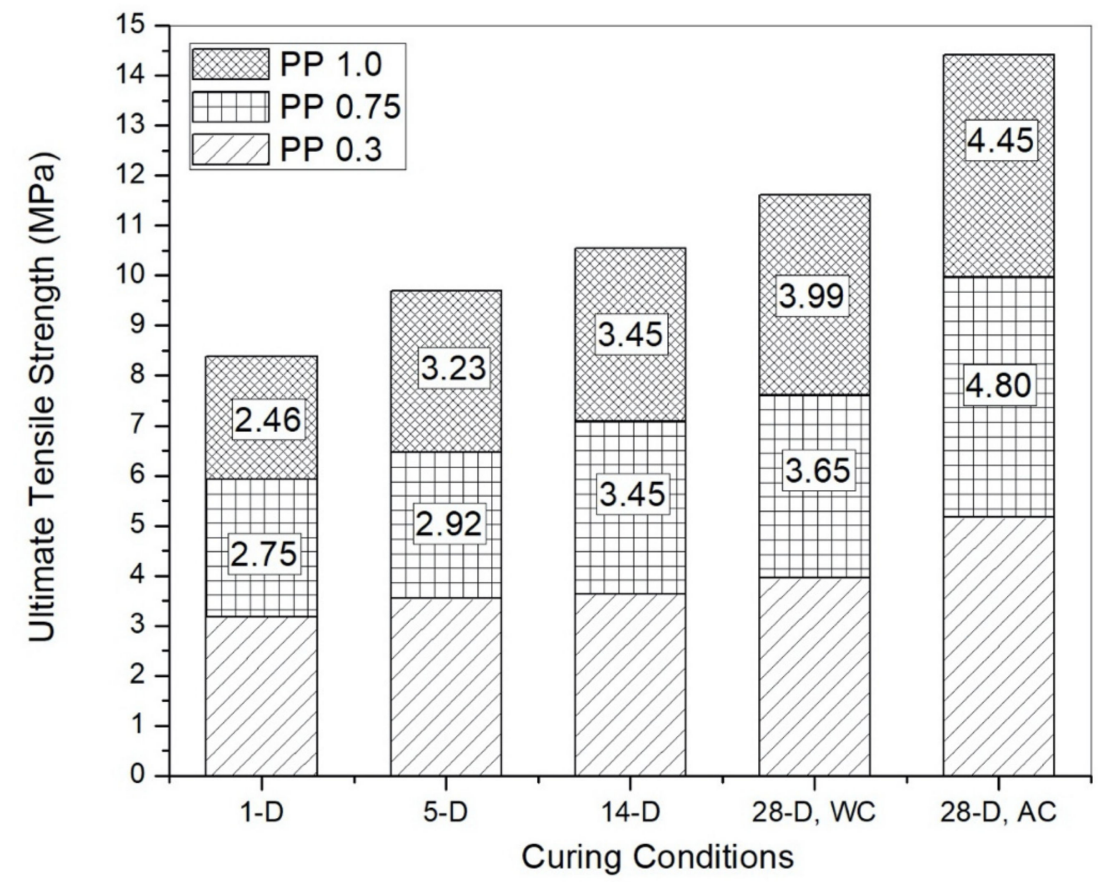

Figure 6. Effect of curing time on ultimate tensile strength of micro PP fibers in PFRCC.

Among the various PFRCC volume fractions, the one containing $0.75 \%$ of micro polypropylene fibers demonstrated the highest positive effect on the tensile strength with $25 \%$ improvement vis-à-vis 5-day water-cured (WC) samples. Furthermore, the results showed that as the curing duration increases, strength is gained for all fiber volume fractions. Interestingly, air-cured (AC) samples at 28 days testing demonstrated higher tensile strength than the ones cured in water for the same duration. The improvement in UTS was recorded at $64 \%$ (2.92 MPa to $4.8 \mathrm{MPa}$ ), $46 \%$, and $38 \%$ for $0.75 \%, 0.3 \%$, and $1.0 \%$ PP fiber volume fractions, respectively, as compared to 5-day water-cured samples. Upon comparing the tensile strength of 28 days and WC with 28 days, AC both 0.3 and $0.75 \mathrm{vol} \%$ fraction illustrated about a $32 \%$ improvement, whereas at a higher volume fraction the increase was only $11 \%$. In the latter case, an increased pore formation may have been the contributing factor.

The fracture behavior of the mortar specimens is equally important and is represented in Figure 7. As can be seen in Figure 7, 0.75\% volume fraction of polypropylene fibers in cementitious paste demonstrates more ductile behavior at the end of 2-day water curing as compared to other volume fractions. A maximum strain increase of $15 \%$ was observed for $0.75 \%$ volume fraction vis-à-vis 1 -day-cured samples. Further, as the curing age increased, a shift from ductile to brittle fracture (i.e., sudden fracture vs. crack propagation) of all the samples was observed. It is interesting to note that the 28-day air-cured samples revealed a higher ductile response as compared to those cured in water for the same duration, where $0.75 \%$ again had a maximum improvement of $23 \%$.

Ductility in civil structures holds importance for many reasons, a few of them are as follows: (i) to provide huge concrete structures with a reinforcement mechanism to transfer the load and be able to redistribute internal actions as the collapse load is approached; (ii) to provide warning measures of a possible collapse by visualizing large cracks prior to a collapse situation; (iii) to enable large deformations and energy to be absorbed by the system without a total collapse in situations such as an earth-quake; and lastly, (iv) to assist in providing robustness, i.e., the ability to withstand un-foreseen local accidents without collapse [62]. 


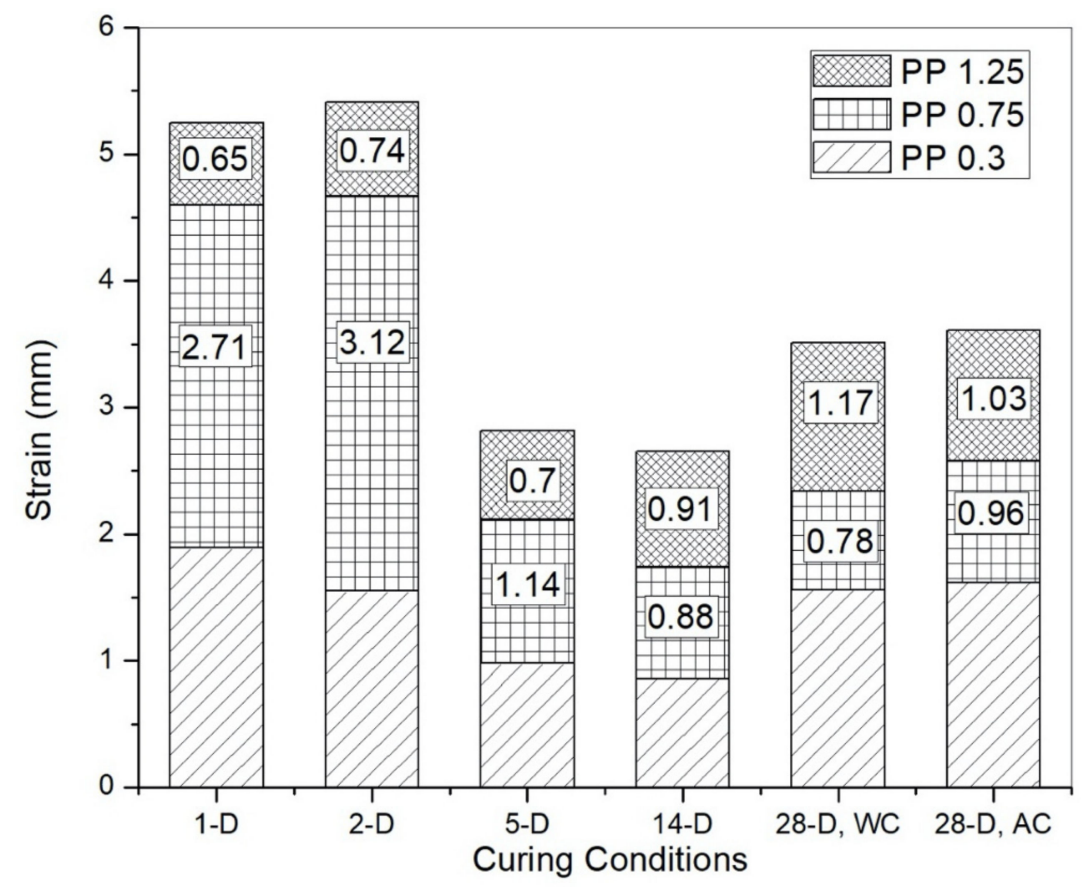

Figure 7. Effect of curing time on strain (fracture response) of micro PP fibers in PFRCC.

In order to investigate the durability perspective further, a fresh batch of mortar mixes (with concentrations $0.3,0.6,0.75$, and $1.0 \mathrm{vol} \%$ ) were cast, but this time, instead of adding PP fibers in the dry mix of cement and sand, they were integrated after a cement paste was produced in the batch mixer. The rationale behind this new trial processing methodology was that lightweight PP fibers would mix homogenously as well as remain confined (in the container) in a wet cementitious matrix as compared to a dry cement-sand mix. The mortar samples (three for each volume fraction) were fabricated, left to cure in water for 1 day or 2 days (based on the findings reported in the above paragraph), and then tested the following day. The experimental results are tabulated in Table 3.

Table 3. Effect of curing time on UTS and strain of micro PP fibers in PFRCC, wet mix condition.

\begin{tabular}{ccccc}
\hline Type of Mix & UTS (MPa)-1-Day Curing & Strain $(\mathbf{m m})$ & UTS $(\mathbf{M P a})-2-D a y$ Curing & Strain $(\mathbf{m m})$ \\
\hline PP 0.3 & 1.61 & 1.89 & 2.86 & 1.55 \\
PP 0.6 & 1.42 & 3.15 & 2.63 & 3.72 \\
PP 0.75 & 1.61 & 2.71 & 2.91 & 3.12 \\
PP 1.0 & 1.27 & 2.46 & 2.65 & 3.62 \\
\hline
\end{tabular}

It can be seen that the general failure process and stress-strain relations of the two batches are similar. As the specimens were loaded, they quickly reached their peak load at a similar strain, and a sudden drop in load was observed, probably due to the matrix cracking internally. However, the load was then transferred to the individual polypropylene fibers that provided residual or post-crack resistance under tensile loading conditions and prevented total failure of the specimens. From Table 3, it can be observed that 0.3 and $0.75 \mathrm{vol} \% \mathrm{PP}$ fiber concentrations in PFRCC have higher tensile strength (1.61 $\mathrm{MPa}$ and about 2.91 MPa) as compared to other concentrations for both 1- and 2-day curing durations. Furthermore, it can be inferred that at 2-day curing, the $0.75 \%$ PP fiber dosage demonstrated more strain capacity along with a higher strength as compared to other samples, especially the $0.3 \%$ dosage. In comparison to the results reported in Table 3 and Figure 7, the samples seemed to be weaker, which is possibly the effect of the wet mixing procedure. The micro polypropylene fibers probably clumped within the cement paste, causing a balling effect [63], and hence impacted the reinforcement efficiency of the system. 
The author's observation that dry mixing supports homogenous dispersion of micro-sized PP fibers in cementitious materials has also been corroborated by other researchers [63].

Figure 8 illustrates how the varying volume fraction of PP fibers in PFRCC are visible to the naked eye. The number of individual fiber strands bearing the applied tensile load is significantly higher for the $0.75 \mathrm{vol} \% \mathrm{PP}$ fiber concentration. It is interesting to note that for $0.3 \mathrm{vol} \%, 5 \%$ less water (than the required amount) was utilized for the casting process, thus resulting in higher strength similar to $0.75 \mathrm{vol} \%$. On the contrary, for the $1.0 \% \mathrm{PP}$ fiber, $5 \%$ extra amount of water was added during the mixing process in order to keep the workability the same as the other samples. As mentioned earlier, the excess water in a cement paste adversely affects its strength (Table 3) as well as durability.

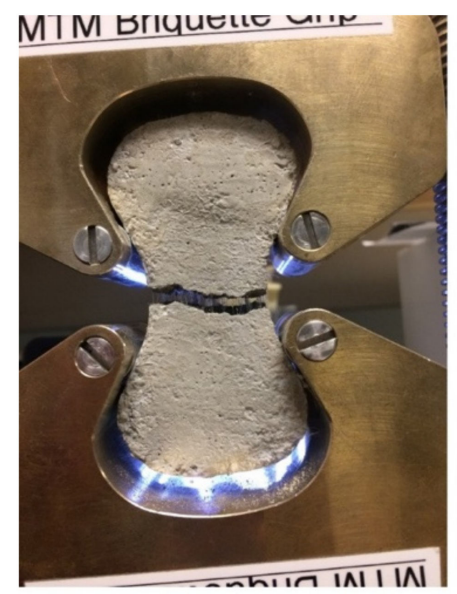

$0.3 \%$ PP fiber

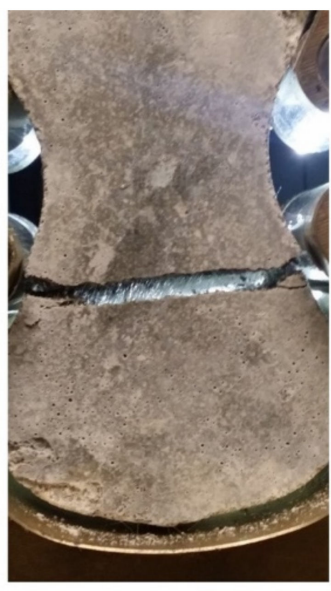

$0.6 \%$ PP fiber

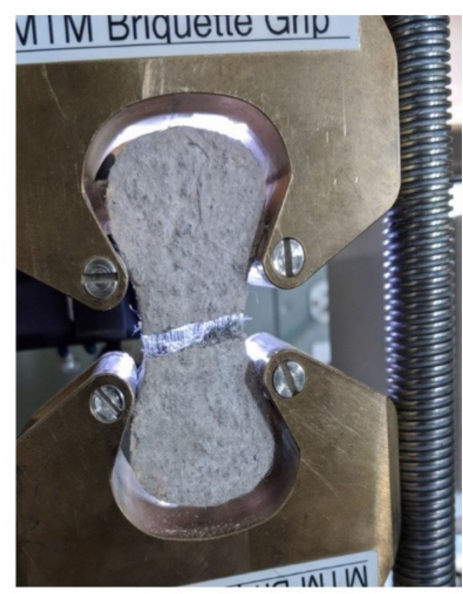

$0.75 \%$ PP fiber

Figure 8. Increased strain response of PP fibers under uniaxial tensile testing.

\subsubsection{Fiber Length}

The length of the fibers also tends to affect the reinforcement efficiency in cementitious materials. In general, fibers with a higher fiber length are harder to disperse, produce more voids, have a lower value of toughness index, and have higher strength until a critical volume fraction is reached [63]. The micro PP fibers have a length of $12 \mathrm{~mm}$, while the macro-sized (MPP) have $50 \mathrm{~mm}$. Based on the author's previous study [41], 0.3\%, 0.6\%, and $1.25 \%$ volume fraction of MPP were chosen to compare the results obtained with micro-sized ones. Furthermore, considering the discussion of Figure 7 and Table 3, less water was used in the mixing process to prepare macro-sized PP fibers reinforced mortar samples, followed by 2-day (48 h) water curing. The results of the maximum uniaxial tensile strength and strain recorded with varying micro- and macro-sized PP fiber volume fractions are presented in Figure 9.

It can be seen that when the volume fraction (Vf) of macro-sized polypropylene fibers was increased from $0.3 \%$ to $0.6 \%$, the load carrying capacity at the peak was greater. However, when the Vf was further increased to $1.25 \%$, the strength value declined probably due to the lower compaction of mix MPP 1.25, which had lower workability. A similar response was also seen earlier when the Vf of micro-sized PP fibers was increased from $0.75 \%$ to $1.0 \%$. The strain behavior in Figure 9 indicates an increase of $140 \%$ and $147 \%$ for $0.75 \%$ PP fiber and $0.3 \%$ MPP samples, respectively, as compared to the plain sample. A visual observation of these two samples is shown in Figure 10. In the specimen with $0.75 \%$ PP fibers, high post-crack strain is evident. During the experiments, the authors observed a higher pull-out force and noticed formation of a uniform crack (in terms of the crack width) across the cross-section of the specimen. As a result, higher strength and post-crack response was observed for PFRCC samples. In terms of the failure pattern, fiber elongation with some fiber pull-out was noticed in the specimen with PP fiber. In Figure 10, it is evident that at larger displacements, MPP fibers pulled out from the matrix. This is typically expected of synthetic fibers. It may also be noted from Figure 9 that although 
1.0\% PP Vf demonstrated a higher ductile response, due to its requirement for additional water, low workability, poor compaction, balling effect, and strength, this volume fraction is not ideal for a hybrid combination. Similar behavior was also seen on increasing the fiber dosage of macro-sized fibers in the cementitious matrix.

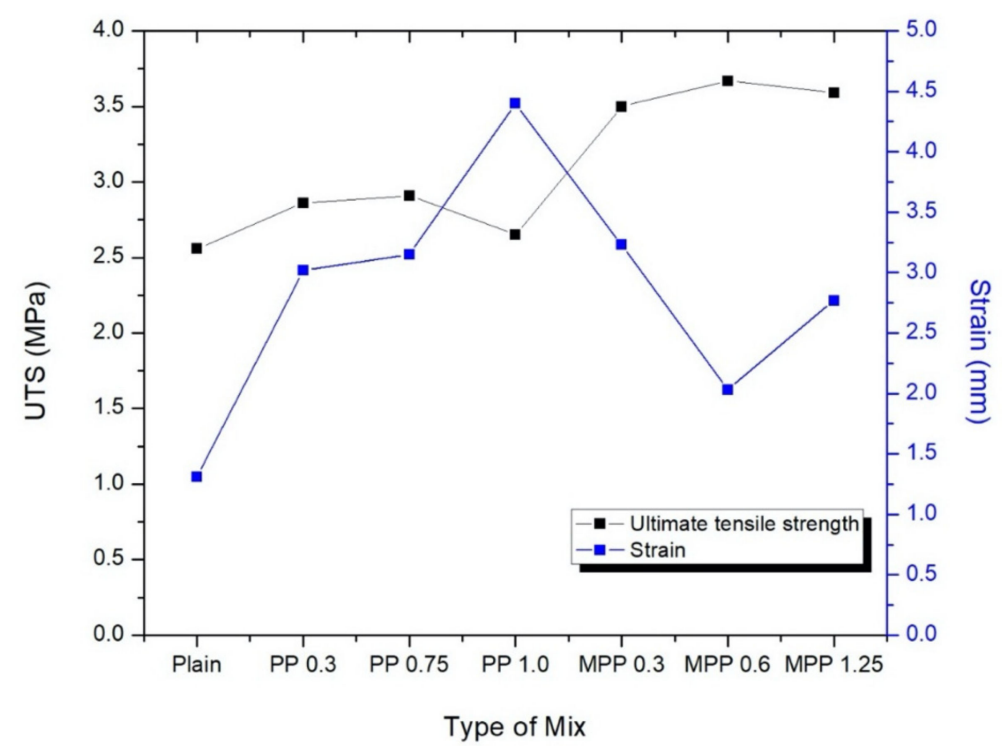

Figure 9. UTS and strain of PFRCC with varying PP and MPP fiber dosages, $48 \mathrm{~h}$ curing.

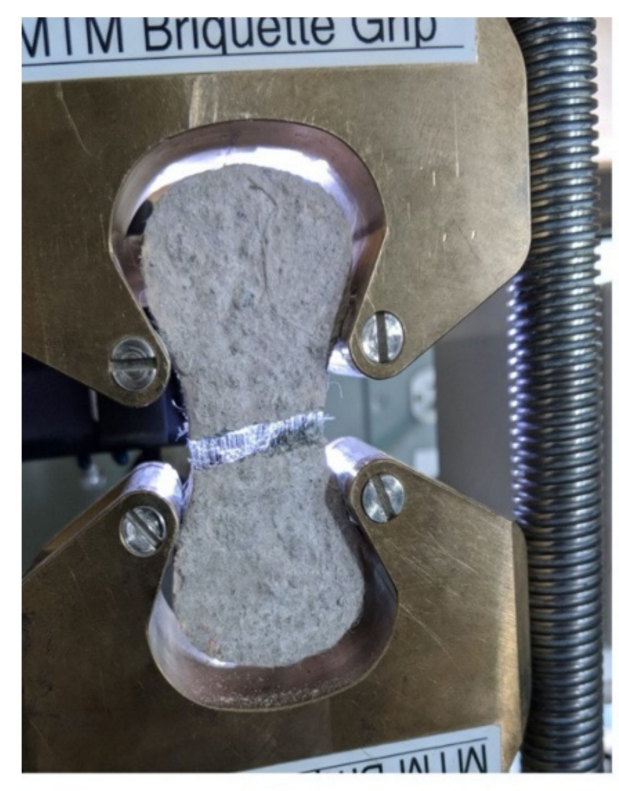

$0.75 \%$ PP fiber

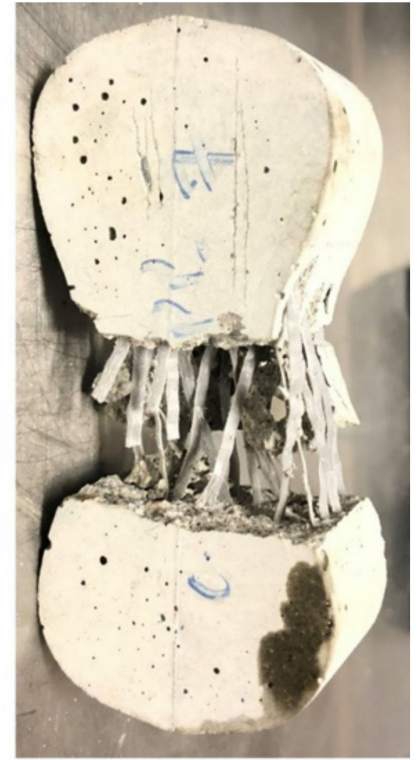

$0.6 \%$ MPP fiber

Figure 10. Failure mechanism of PP and MPP fibers under uniaxial tensile testing.

The above results indicate that integrating macro polypropylene fibers (MPP) significantly improves the concrete tensile strength relative to micro polypropylene (PP) fibers. Due to their crimped shape, a stronger bond is formed with the cement matrix; their long length and high tensile strength prevent the post-cracking macro-crack propagation, and finally, improve their tensile strength. On the other hand, micro polypropylene fibers have shorter length and lower tensile strength vis-à-vis MPP fibers, which is probably the reason as to why its maximum strength is lower than what was recorded for MPP fibers. A similar response of fiber length and strength properties in fiber-reinforced concrete has also been reported previously $[2,64]$. 
Hence, based on the experimental results so far, it can be stated that for $0.3 \% \mathrm{MPP}$ $\mathrm{V}_{\mathrm{f}}$ either of $0.3 \% \mathrm{PP}$ or $0.75 \%$ PP would develop a high strength and durable hybrid FRCC material that would demonstrate both improvement in strength as well as ductility behavior. Based on the results obtained, this is considered the future scope of this study.

\subsection{Compressive Strength}

To further examine the contribution of polypropylene fibers to the compressive strength of PFRCC materials, compressive tests were carried out on small cube specimens with varying volume fraction of micro- (PP 0.3\%, 0.75\%, and 1.25\%) and macro-sized (MPP 0.3\%, 0.6\%, and 1.25\%) polypropylene fibers. Three specimens were prepared and tested for each batch. During the tests, the load change along with time (in seconds) was also recorded to observe the reinforcement efficiency of PP fibers in FRC materials. The average strength of different mixes when cured for 2 days ( $48 \mathrm{~h}$ ) was compared, as shown in Figure 11.

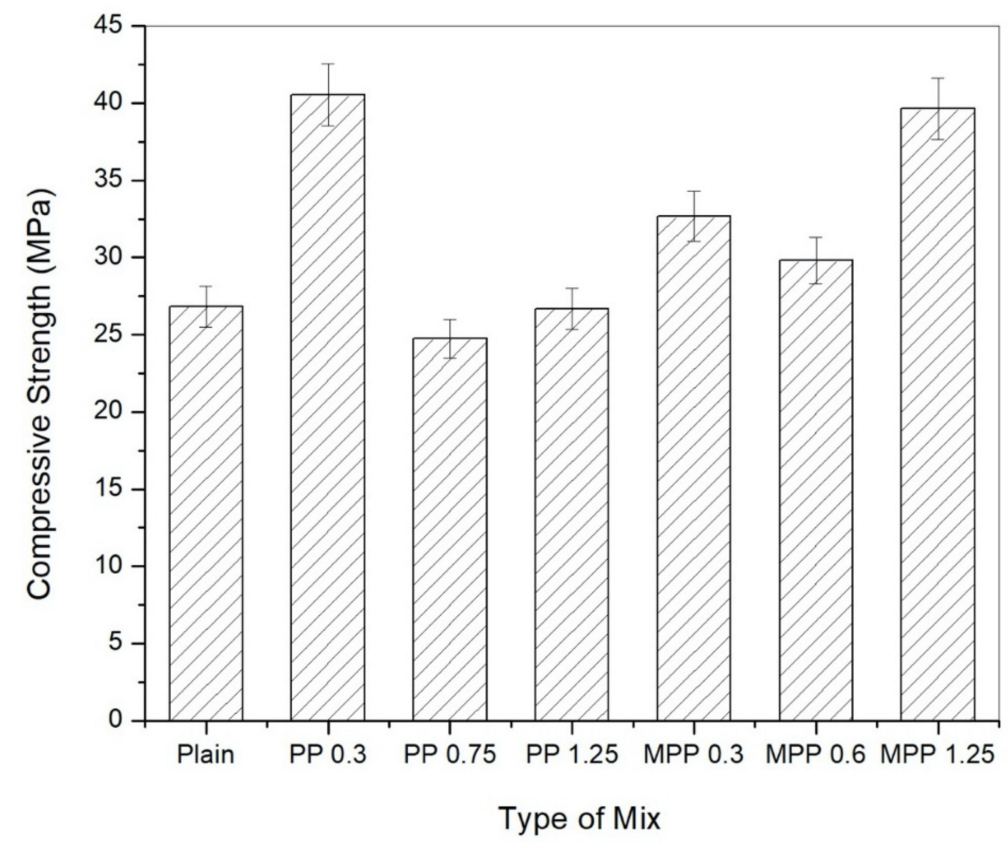

Figure 11. Compressive strength of PFRCC with varying PP and MPP fiber dosages, $48 \mathrm{~h}$ curing.

The mortar samples with macro and micro polypropylene fibers with $0.3 \%$ and $1.25 \%$ volume fraction demonstrated the maximum improvement in the compressive strength with $51 \%$ and $48 \%$ increase, respectively. It was observed that in low volume fractions, the effect of macro PP fibers on the compressive strength was greater in comparison with that of the micro PP fibers. In general, the enhancement in compressive strength of FRCC materials is attributed to the ability of fibers to restrain and delay crack propagation, while the matrix cracks slowly. However, during the testing, the authors observed that near the specimen failure, the micro PP fibers came into play, preventing further crack propagation throughout the sample, which resulted in higher efficiency in bridging micro-cracks and consequently, increasing the ductility. On the other hand, because of their macro scale and greater length, the MPP fibers were able to handle more load until the peak load to failure was attained, beyond which the macro fibers were unable to bridge the micro-cracks and improve the ductility of the PFRCC material. The load-time curves of the PFRCC cubes with micro and macro PP fibers reinforced in a cementitious matrix were plotted after the peak load was attained and specimen failure was initiated, and the recording was stopped when the load dropped below 19KN. The sample that represented the closest value to the average (in each batch) is presented in Figure 12. It can be seen that the general failure behavior and load-time relations of the two specimen fiber types are similar. For instance, for $0.3 \%$ 
and $0.75 \%$ micro-scale fiber volume fraction specimens (refer to Figure 12a), immediately after reaching the peak resistance, the load dropped suddenly due to the cracking of the mortar matrix. Following that, the fibers were effective in bridging the cracks and provided residual or post-cracking resistance under continuous compressive loading.
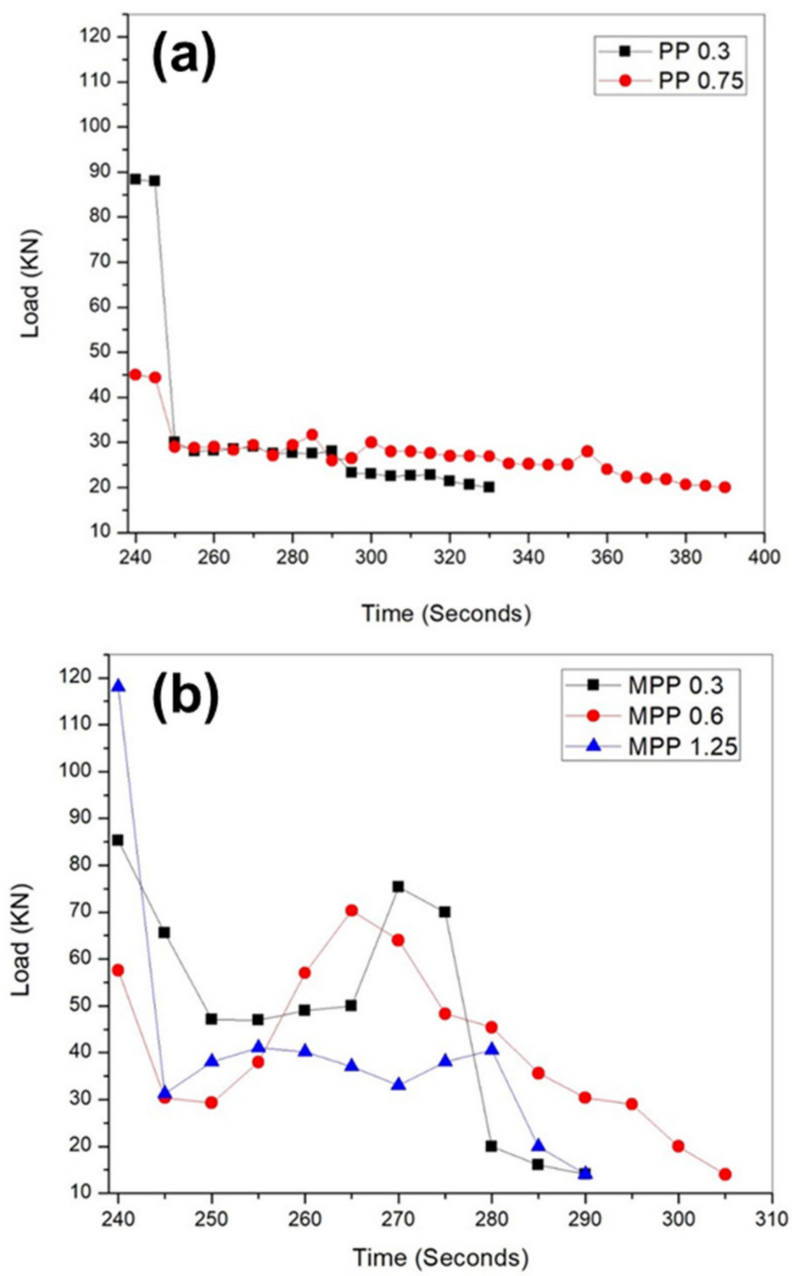

Figure 12. Load vs. time graph of (a) micro PP and (b) macro PP PFRCC samples during compressive tests.

In the case of macro PP fiber cube specimens (refer to Figure 12b), the authors observed greater post-crack resistance up to failure, while the micro PP fiber specimens demonstrated further resistance against the surface micro-cracks due to their micro scale, as shown in Figure 13.
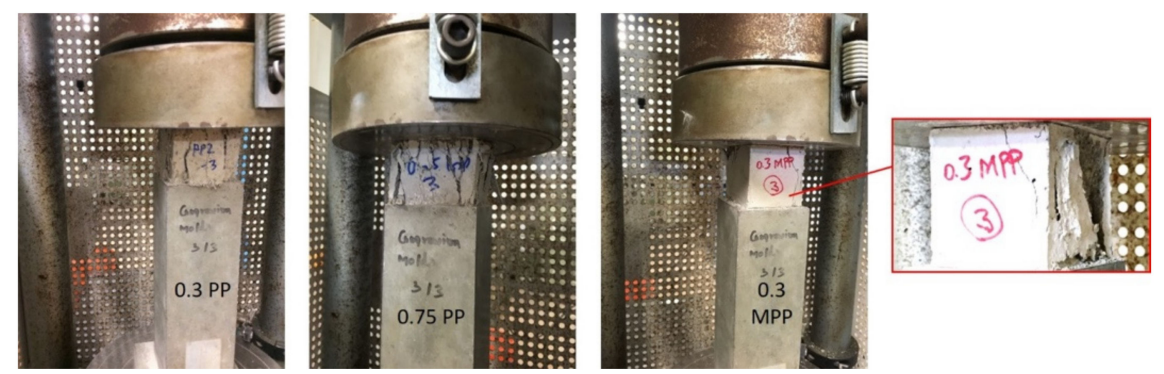

Figure 13. Fracture response of PFRCC specimens under compressive loading conditions. 


\subsection{Post-Crack Strength/Energy}

Once a crack forms in a fiber-reinforced cementitious composite, the matrix resists minimal and external load at the cracked plane and most of the applied load is then supported by the fibers. This implies that the tensile behavior of a FRCC sample is determined absolutely by the pull-out behavior of the fibers embedded in the matrix. The post-cracking behavior of a composite can be defined as the combination of the resistance provided by the fibers and the matrix. Load-deflection graphs were obtained for a deflection corresponding to at least three times that of the recorded crack initiation $\left(\delta_{\text {peak }}\right)$. Based on each sample's crack initiation point, its post-crack strength was calculated for $2 \delta$ and $3 \delta$.

Figure 14 depicts the load-displacement curve for one sample mix and $0.75 \%$ volume micro PP fiber concentration, when cured for 1 day, 2 days, and 5 days. It can be clearly seen that as the curing age increases to 5 days, there is an increase in peak load (from $1512 \mathrm{~N}$ to $1627 \mathrm{~N}$ to a max of $2134 \mathrm{~N}$ ). Post crack at peak load, the load plunges and reaches a certain load at which the fibers hold the sample intact and prevent it from total failure. The post-crack loads were recorded as $230 \mathrm{~N}$ (at $0.55 \mathrm{~mm}$ ), $52 \mathrm{~N}$ (at $1.56 \mathrm{~mm}$ ), and $35 \mathrm{~N}$ (at $1.48 \mathrm{~mm}$ ) for 1-day-, 2-day- and 5-day-cured samples, respectively. These results again suggest that cement hydration affects the load bearing capacity of the sample and the resulting fracture response (as observed earlier). Upon plotting the 2-day- and 5-day-cured load-displacement curves for the $1.25 \mathrm{vol} \%$ micro PP fiber, a similar response was observed, as shown in Figure 15.

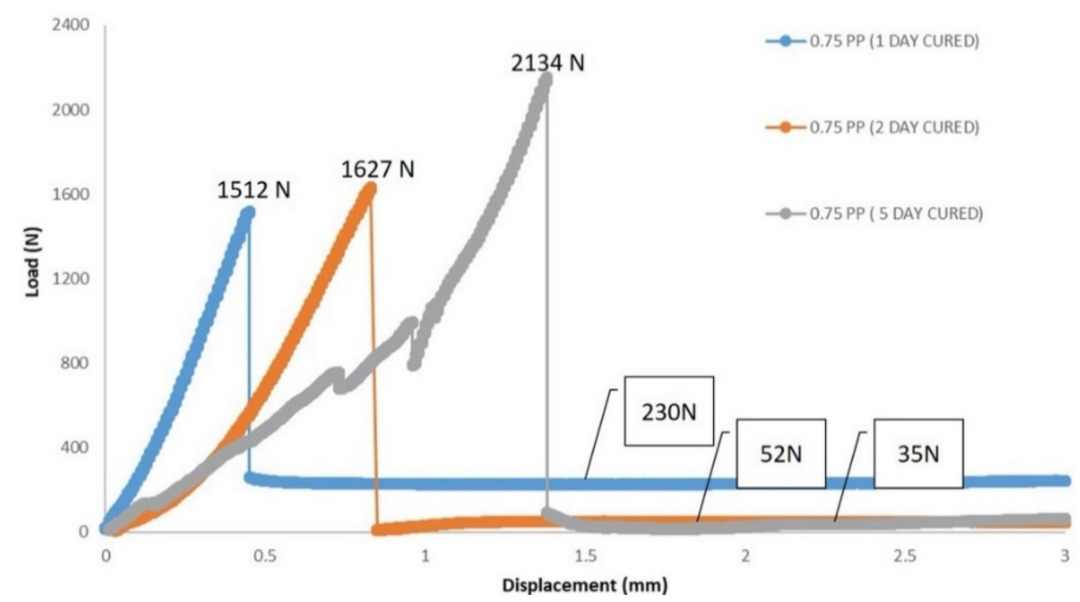

Figure 14. Load-displacement curve for 0.75 vol\% micro PP in PFRCC materials.

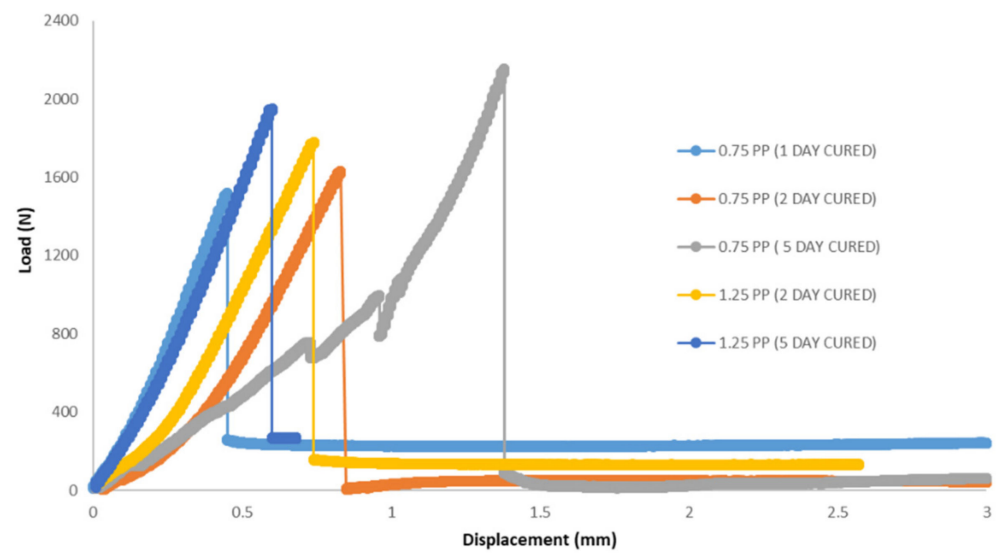

Figure 15. Load-displacement curve for 0.75 and $1.25 \mathrm{vol} \%$ micro PP in PFRCC materials for varying curing durations. 
The load-displacement curves (refer to Figure 16) for 0.3 and 0.6 vol\% macro PP fibers illustrated higher peak loads for initial crack, post-crack, and significant ductile response as compared to micro PP fiber reinforcement. The maximum post-crack peak loads were recorded to be $1085 \mathrm{~N}$ and $2400 \mathrm{~N}$ for 0.3 and $0.6 \%$ volume fractions, respectively. It is also interesting to note that there is a gradual decrease in the load that macro fibers can handle until the specimen fails totally. On the contrary, in the case of micro-scale fibers, the load either increased or remained stable at a much lower load level.

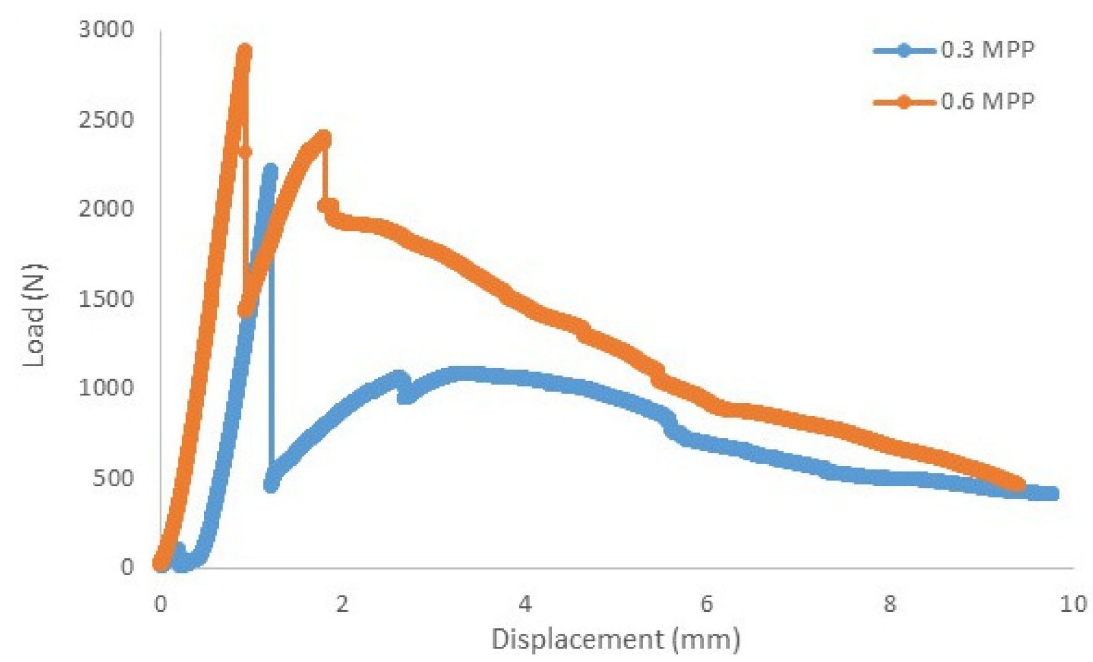

Figure 16. Load-displacement curve for 0.3 and 0.6 vol\% macro PP in PFRCC materials, $48 \mathrm{~h}$ curing.

\subsection{Self-Healing Mechanism}

Considering the promising behavior of micro PP fibers in the samples described in the above sections, the authors decided to explore the self-healing mechanism for the $1.0 \mathrm{vol} \%$ micro PP mix. In order to prepare a sample that could self-heal, the crack width needed to be less than $0.5 \mathrm{~mm}$. Some studies had previously reported self-healing potential using supplementary admixtures for a crack width up to $0.5 \mathrm{~mm}[4,8,12,20,36,37,40,47]$.

During uniaxial tensile testing of the micro PFRCC specimens, the authors monitored the deflection of the sample and stopped the MTM machine as soon as it reached $0.5 \mathrm{~mm}$. The crack width was verified using a crack width microscope. However, only three samples with $1.0 \mathrm{vol} \%$ micro PP fiber dosage that did not break into two pieces could be recovered for the self-healing investigation. In this pilot study, the cracked samples were immersed in water for 40 days at ambient temperature without any additional supplementary admixtures to explore the self-healing potential.

Following the 40-day water curing, the samples were air dried and tested under tensile loading conditions to observe their performance. The objective was to observe the maximum load a healed specimen could withstand. For the three samples that were healed, an average load of $146 \mathrm{~N}$ and an average displacement of $9.46 \mathrm{~mm}$ were recorded. In Figure 17, the initial load-displacement of one of those three samples along with its healing load displacement behavior is illustrated. It can be clearly seen that the sample (1.0 vol\% micro PP fibers) had an initial peak load of $2000 \mathrm{~N}$ prior to the crack with $0.7 \mathrm{~mm}$ displacement. However, upon reloading that same specimen, a maximum load of $209 \mathrm{~N}$ with a displacement of $12.4 \mathrm{~mm}$ was recorded. These results clearly demonstrated that the fiber-matrix interface had healed to a greater extent, which lays the foundation to explore this even further. 


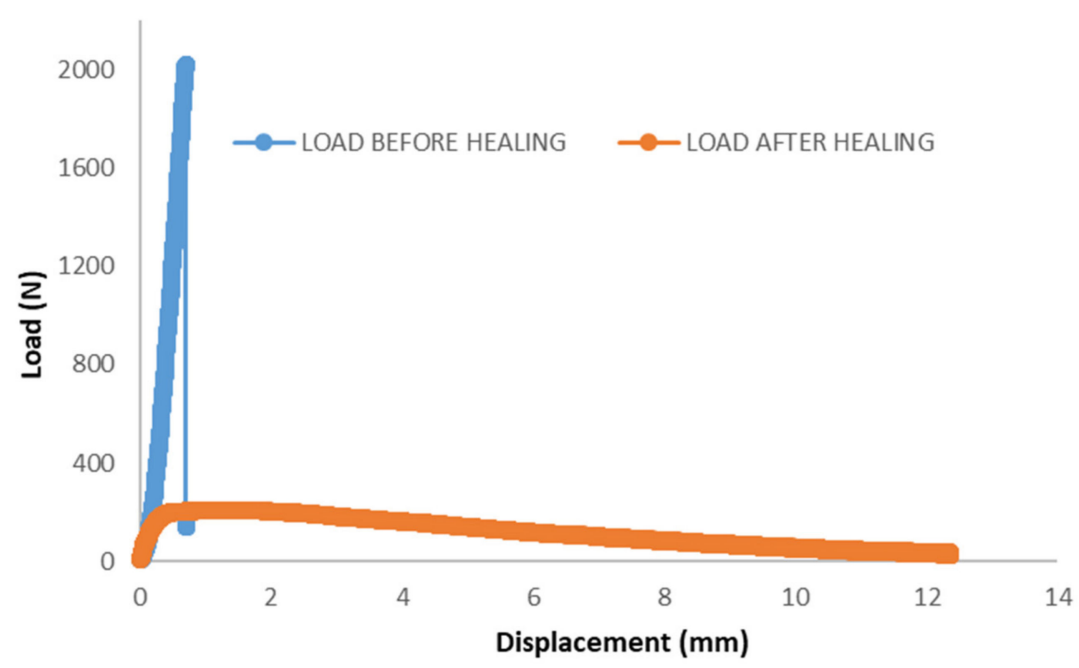

Figure 17. Load vs. displacement plot for healed specimen.

The rationale that possibly supports the self-healing mechanism in these samples is as follows: these samples were initially cured for $24 \mathrm{~h}$ (1 day); thus, they lacked the completion of the cement hydration process, which tends to increase the formation of C-S-H gels as well as calcite formation $\left(\mathrm{CaCO}_{3}\right)$ that promotes a better interfacial zone. By curing the cracked specimen for 40 days in water, it was assumed that the unreacted cement inside the sample reacted with the water to produce calcium hydroxide and C-S-H, which on crystallizing, healed those cracks. In addition to that, the presence of fibers internally created a bridge in the gap between the two sides of the crack, which provided enough time for the cement matrix to heal itself. As a result, the healed sample (refer to Figure 18) was efficient enough to handle additional load and deformation under natural environmental conditions. A study by Herbert and $\mathrm{Li}$ [43] also demonstrated the potential of the self-healing mechanism in engineered cementitious materials when exposed to natural environmental conditions.

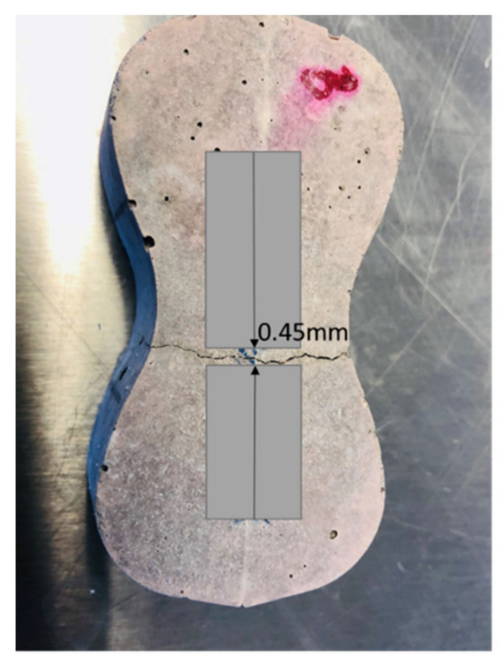

Initial cracking - controlled

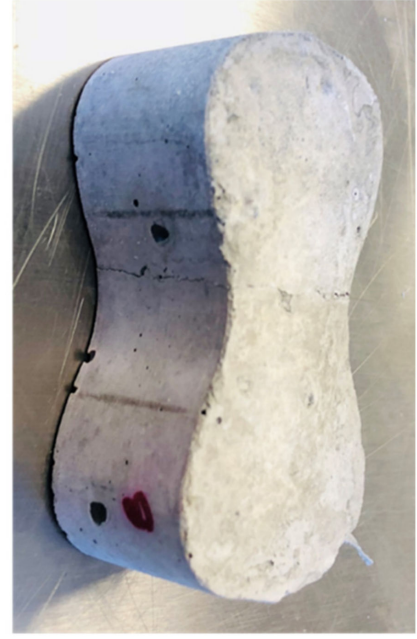

Crack healed under normal conditions

Figure 18. Controlled crack that healed under normal conditions.

The benefit of this pilot study on the self-healing of PFRCC materials suggests that if concrete is cracked due to normal wear and tear conditions (up to a certain crack width), when exposed to natural rain or water it holds the potential to heal itself. A comparison between different failure mechanisms observed in this study for PFRCC samples and how the reinforcement of PP fibers along with the curing schedule has changed the performance 


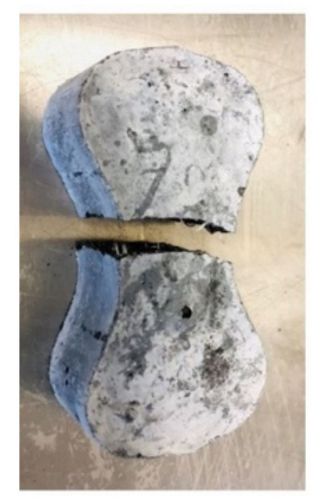

Brittle

of FRCC is represented in Figure 19. Based on the results obtained, the authors plan to also extend this scope of self-healing to other samples.

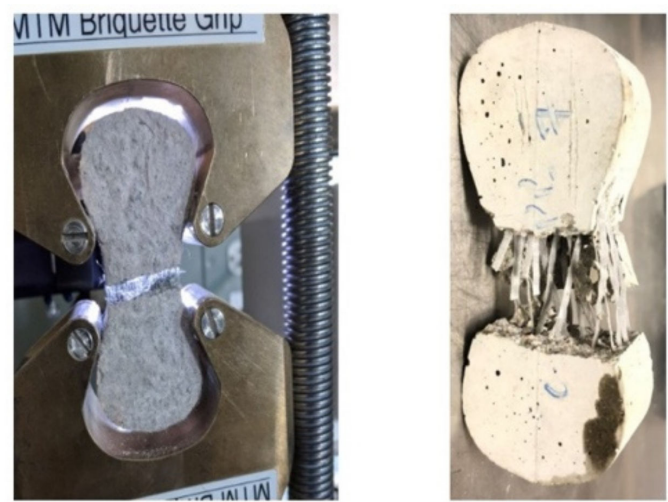

Ductile / Post Crack

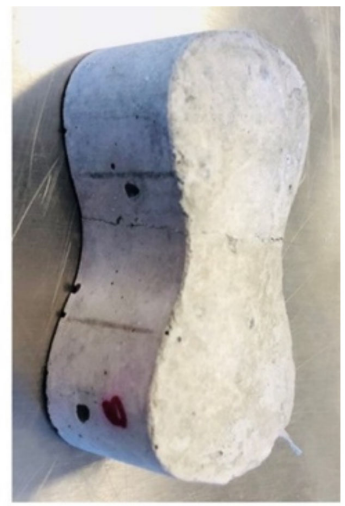

Crack - healed

Figure 19. Different responses of PP fiber reinforced concrete with varying curing conditions.

\section{Conclusions}

Based on the experimental work performed in this research, the following conclusions can be drawn:

1. Micro PP fibers at low volume fractions $\left(\mathrm{V}_{\mathrm{f}}\right)$ showed promising response in restraining the development of micro-cracks and thus supported the delaying of the crack propagation through the mortar specimens. On the contrary, higher $\mathrm{V}_{\mathrm{f}}$ not only adds to the cost but also leads to an increased porosity and fiber clumping.

2. A total of $0.75 \% \mathrm{~V}_{\mathrm{f}}$ of micro polypropylene fibers revealed a $25 \%$ increase in strength at the end of 28 days (water curing) vis-à-vis 5-day-cured samples. Further, a similar sample that was cured in air (up to 28 days) post initial 5-day water curing demonstrated a $64 \%$ increase in strength.

3. The fracture response was also observed to transition from ductile to brittle as the curing time (less than 28 days) increased for FRCC materials. The presence of extra water in the system made the cement paste weaker and more susceptible to cracking and shrinkage. For instance, $0.75 \% \mathrm{~V}_{\mathrm{f}}$ reported a maximum strain of $3.12 \mathrm{~mm}$ for 2-day curing as compared to $0.78 \mathrm{~mm}$ for 28-day curing.

4. Another important factor that was investigated was the mixing condition of polypropylene fibers in the cementitious matrix. Based on the experimental results (in terms of strength and strain), better performance was observed when the fibers were integrated in a dry mix of cement and sand as compared to a wet mix (i.e., cement paste).

5. Moreover, the length of polypropylene fibers also had a profound effect on the strength of FRCC material. Higher fiber length supported higher tensile and compressive strength as compared to short (micro) fibers. For instance, 2-day-cured samples demonstrated an improvement in strain of $140 \%$ and $147 \%$ for $0.75 \% \mathrm{~V}_{\mathrm{f}}$ (micro scale) and $0.3 \% \mathrm{~V}_{\mathrm{f}}$ (macro scale) samples, respectively. Observing the samples carefully during testing clearly illustrated that the presence of micro-scale PP fibers resists against micro-cracks, thus improving the ductility of the material. In contrast, the macro-scale PP fibers promote strength enhancement. Hence, an optimal concentration as a hybrid mix $\left(\mathrm{V}_{\mathrm{f}}: 0.75 \%\right.$ for micro scale and $0.3 \%$ for macro scale) could provide a robust material for industrial application and should be further investigated.

6. Lastly, a FRCC sample with a controlled micro-crack of $0.45 \mathrm{~mm}$ width healed under natural environmental conditions, thus, promoting the 'Self-healing' mechanism in cementitious materials. 
In brief, the experimental results of this pilot study on the self-healing of PFRCC materials provide evidence that if concrete is cracked due to normal wear and tear conditions (up to a certain crack width), when exposed to natural rain or water it holds the potential to heal itself. In addition to this benefit, the authors' findings about mixing procedure, proportions, length of fibers, and optimal fiber volume fraction, for one of the common synthetic fibers used by the construction industry as a secondary reinforcement, are some of the other key contributions.

Author Contributions: Conceptualization, M.G. and P.A.; methodology, P.A.; formal analysis, M.G.; investigation, M.G. and P.A.; resources, M.G. and P.A.; data collection and analysis, M.G.; writingoriginal draft preparation, M.G.; writing—review and editing, M.G. and P.A.; visualization, M.G.; supervision, R.G.; project administration, R.G.; funding acquisition, R.G.; All authors have read and agreed to the published version of the manuscript.

Funding: This research received no external funding.

Data Availability Statement: The data will be made available upon request.

Acknowledgments: The authors would like to acknowledge the contribution of Propex Inc. for their donation of the fibers used in this study.

Conflicts of Interest: The authors declare no conflict of interest.

\section{References}

1. Afroughsabet, V.; Ozbakkaloglu, T. Mechanical and durability properties of high-strength concrete containing steel and polypropylene fibers. Constr. Build. Mater. 2015, 94, 73-82. [CrossRef]

2. Fallah, S.; Nematzadeh, M. Mechanical properties and durability of high-strength concrete containing macro-polymeric and polypropylene fibers with nano-silica and silica fume. Constr. Build. Mater. 2017, 132, 170-187. [CrossRef]

3. Jefferson, A.; Joseph, C.; Lark, R.; Isaacs, B.; Dunn, S.; Weager, B. A new system for crack closure of cementitious materials using shrinkable polymers. Cem. Concr. Res. 2010, 40, 795-801. [CrossRef]

4. Van Tittelboom, K.; de Belie, N. Self-Healing in Cementitious Materials-A Review. Materials 2013, 6, 2182-2217. [CrossRef]

5. Li, M.; Li, V.C. Cracking and Healing of Engineered Cementitious Composites under Chloride Environment. Mater. J. 2011, 108, M36.

6. Şahmaran, M.; Keskin, S.B.; Ozerkan, G.; Yaman, I.O. Self-healing of mechanically-loaded self-consolidating concretes with high volumes of fly ash. Cem. Concr. Compos. 2008, 30, 872-879. [CrossRef]

7. Yang, Y.; Lepech, M.D.; Yang, E.-H.; Li, V.C. Autogenous healing of engineered cementitious composites under wet-dry cycles. Cem. Concr. Res. 2009, 39, 382-390. [CrossRef]

8. Reinhardt, H.-W.; Jooss, M. Permeability and self-healing of cracked concrete as a function of temperature and crack width. Cem. Concr. Res. 2003, 33, 981-985. [CrossRef]

9. Ramm, W.; Biscoping, M. Autogenous healing and reinforcement corrosion of water-penetrated separation cracks in reinforced concrete. Nucl. Eng. Des. 1998, 179, 191-200. [CrossRef]

10. Hearn, N.; Morley, C.T. Self-sealing property of concrete-Experimental evidence. Mater. Struct. 1997, 30, 404-411. [CrossRef]

11. Neville, A. Autogenous Healing-A Concrete Miracle? Concr. Int. 2002, 24, 76-82.

12. Granger, S.; Loukili, A.; Pijaudier-Cabot, G.; Chanvillard, G. Experimental characterization of the self-healing of cracks in an ultra-high-performance cementitious material: Mechanical tests and acoustic emission analysis. Cem. Concr. Res. 2007, 37, 519-527. [CrossRef]

13. Zamorowski, W. The phenomenon of self-regeneration of concrete. Int. J. Cem. Compos. Lightweight Concr. 1985, 7, 199-201. [CrossRef]

14. Hearn, N. Self-sealing, autogenous healing and continued hydration: What is the difference? Mater. Struct. 1998, $31,563$. [CrossRef]

15. Jacobsen, S.; Sellevold, E.J. Self-healing of high strength concrete after deterioration by freeze/thaw. Cem. Concr. Res. 1996, 26, 55-62. [CrossRef]

16. Aldea, C.-M.; Song, W.-J.; Popovics, J.S.; Shah, S.P. Extent of Healing of Cracked Normal Strength Concrete. J. Mater. Civ. Eng. 2000, 12, 92-96. [CrossRef]

17. Sahmaran, M.; Li, M.; Li, V.C. Transport Properties of Engineered Cementitious Composites under Chloride Exposure. Mater. J. 2007, 104, 604 .

18. Jacobsen, S.; Marchand, J.; Boisvert, L. Effect of cracking and healing on chloride transport in OPC concrete. Cem. Concr. Res. 1996, 26, 869-881. [CrossRef]

19. Snoeck, D.; de Belie, N. Mechanical and self-healing properties of cementitious composites reinforced with flax and cottonised flax, and compared with polyvinyl alcohol fibres. Biosyst. Eng. 2012, 111, 325-335. [CrossRef] 
20. Homma, D.; Mihashi, H.; Nishiwaki, T. Self-Healing Capability of Fibre Reinforced Cementitious Composites. J. Adv. Concr. Technol. 2009, 7, 217-228. [CrossRef]

21. Edvardsen, C. Water Permeability and Autogenous Healing of Cracks in Concrete. Mater. J. 1999, 96, $473-487$.

22. Azarsa, P.; Gupta, R.; Biparva, A. Assessment of self-healing and durability parameters of concretes incorporating crystalline admixtures and Portland Limestone Cement. Cem. Concr. Compos. 2019, 99, 17-31. [CrossRef]

23. Ahn, T.-H.; Kishi, T. Crack Self-healing Behavior of Cementitious Composites Incorporating Various Mineral Admixtures. J. Adv. Concr. Technol. 2010, 8, 171-186. [CrossRef]

24. Sisomphon, K.; Copuroglu, O.; Koenders, E.A.B. Self-healing of surface cracks in mortars with expansive additive and crystalline additive. Cem. Concr. Compos. 2012, 34, 566-574. [CrossRef]

25. Song, G.; Ma, N.; Li, H.-N. Applications of shape memory alloys in civil structures. Eng. Struct. 2006, 28, 1266-1274. [CrossRef]

26. Wiktor, V.; Jonkers, H.M. Quantification of crack-healing in novel bacteria-based self-healing concrete. Cem. Concr. Compos. 2011, 33, 763-770. [CrossRef]

27. Wang, J.; van Tittelboom, K.; de Belie, N.; Verstraete, W. Use of silica gel or polyurethane immobilized bacteria for self-healing concrete. Constr. Build. Mater. 2012, 26, 532-540. [CrossRef]

28. Wang, J.Y.; Snoeck, D.; van Vlierberghe, S.; Verstraete, W.; de Belie, N. Application of hydrogel encapsulated carbonate precipitating bacteria for approaching a realistic self-healing in concrete. Constr. Build. Mater. 2014, 68, 110-119. [CrossRef]

29. Van Tittelboom, K.; de Belie, N.; de Muynck, W.; Use, W.V. of bacteria to repair cracks in concrete. Cem. Concr. Res. 2010, 40, 157-166. [CrossRef]

30. Dry, C. Procedures developed for self-repair of polymer matrix composite materials. Compos. Struct. 1996, 35, 263-269. [CrossRef]

31. Dry, C. Matrix cracking repair and filling using active and passive modes for smart timed release of chemicals from fibers into cement matrices. Smart Mater. Struct. 1994, 3, 118. [CrossRef]

32. Dry, C.; McMillan, W. Three-part methylmethacrylate adhesive system as an internal delivery system for smart responsive concrete. Smart Mater. Struct. 1996, 5, 297. [CrossRef]

33. Li, V.C.; Lim, Y.M.; Chan, Y.-W. Feasibility study of a passive smart self-healing cementitious composite. Compos. Part B Eng. 1998, 29, 819-827. [CrossRef]

34. Joseph, C.; Jefferson, A.D.; Isaacs, B.; Lark, R.; Gardner, D. Experimental investigation of adhesive-based self-healing of cementitious materials. Mag. Concr. Res. 2010, 62, 831-843. [CrossRef]

35. Thao, T.D.P.; Johnson, T.J.S.; Tong, Q.S.; Dai, P.S. Implementation of self-healing in concrete-Proof of concept. IES J. Part Civ. Struct. Eng. 2009, 2, 116-125. [CrossRef]

36. Nishiwaki, T.; Mihashi, H.; Jang, B.-K.; Miura, K. Development of Self-Healing System for Concrete with Selective Heating around Crack. J. Adv. Concr. Technol. 2006, 4, 267-275. [CrossRef]

37. Pang, J.W.C.; Bond, I.P. A hollow fibre reinforced polymer composite encompassing self-healing and enhanced damage visibility. Compos. Sci. Technol. 2005, 65, 1791-1799. [CrossRef]

38. Bleay, S.; Loader, C.; Hawyes, V.; Humberstone, L.; Curtis, P. A smart repair system for polymer matrix composites. Compos. Part Appl. Sci. Manuf. 2001, 32, 1767-1776. [CrossRef]

39. Motuku, M.; Vaidya, U.K.; Janowski, G.M. Parametric studies on self-repairing approaches for resin infused composites subjected to low velocity impact. Smart Mater. Struct. 1999, 8, 623. [CrossRef]

40. Qian, S.; Zhou, J.; de Rooij, M.R.; Schlangen, E.; Ye, G.; van Breugel, K. Self-healing behavior of strain hardening cementitious composites incorporating local waste materials. Cem. Concr. Compos. 2009, 31, 613-621. [CrossRef]

41. El-Newihy, A.; Azarsa, P.; Gupta, R.; Biparva, A. Effect of Polypropylene Fibers on Self-Healing and Dynamic Modulus of Elasticity Recovery of Fiber Reinforced Concrete. Fibers 2018, 6, 9. [CrossRef]

42. Kan, L.L.; Shi, H.S.; Sakulich, A.R.; Li, V.C. Self-Healing Characterization of Engineered Cementitious Composite Materials. Mater. J. 2010, 107, M70.

43. Herbert, E.; Li, V. Self-Healing of Microcracks in Engineered Cementitious Composites (ECC) Under a Natural Environment. Materials 2013, 6, 2831-2845. [CrossRef] [PubMed]

44. Özbay, E.; Sahmaran, M.; Lachemi, M.; Yücel, H.E. Self-Healing of Microcracks in High-Volume Fly-Ash- Incorporated Engineered Cementitious Composites. Mater. J. 2013, 110, 33.

45. Sahmaran, M.; Yildirim, G.; Erdem, T.K. Self-healing capability of cementitious composites incorporating different supplementary cementitious materials. Cem. Concr. Compos. 2013, 35, 89-101. [CrossRef]

46. Şahmaran, M.; Yildirim, G.; Ozbay, E.; Ahmed, K.; Lachemi, M. Self-healing ability of cementitious composites: Effect of addition of pre-soaked expanded perlite. Mag. Concr. Res. 2014, 66, 409-419. [CrossRef]

47. Yildirim, G.; Sahmaran, M.; Ahmed, H.U. Influence of Hydrated Lime Addition on the Self-Healing Capability of High-Volume Fly Ash Incorporated Cementitious Composites. J. Mater. Civ. Eng. 2015, 27, 04014187. [CrossRef]

48. Behfarnia, K.; Behravan, A. Application of high-performance polypropylene fibers in concrete lining of water tunnels. Mater. Des. 2014, 55, 274-279. [CrossRef]

49. Caggiano, A.; Gambarelli, S.; Martinelli, E.; Nisticò, N.; Pepe, M. Experimental characterization of the post-cracking response in Hybrid Steel/Polypropylene Fiber-Reinforced Concrete. Constr. Build. Mater. 2016, 125, 1035-1043. [CrossRef] 
50. Kawashima, K.; Zafra, R.; Sasaki, T.; Kajiwara, K.; Nakayama, M. Effect of Polypropylene Fiber Reinforced Cement Composite and Steel Fiber Reinforced Concrete for Enhancing the Seismic Performance of Bridge Columns. J. Earthq. Eng. 2011, 15, $1194-1211$. [CrossRef]

51. Alberti, M.G.; Enfedaque, A.; Gálvez, J.C. On the prediction of the orientation factor and fibre distribution of steel and macrosynthetic fibres for fibre-reinforced concrete. Cem. Concr. Compos. 2017, 77, 29-48. [CrossRef]

52. Siddika, A.; Mamun, M.A.; Ferdous, W.; Saha, A.K.; Alyousef, R. 3D-printed concrete: Applications, performance, and challenges. J. Sustain. Cem. Based Mater. 2019, 9, 127-164. [CrossRef]

53. Ferdous, W.; Manalo, A.; AlAjarmeh, O.; Mohammed, A.; Salih, C.; Yu, P.; Khotbehsara, M.M.; Schubel, P. Static behaviour of glass fibre reinforced novel composite sleepers for mainline railway track. Eng. Struct. 2021, 229, 111627. [CrossRef]

54. Alberti, M.G.; Enfedaque, A.; Gálvez, J.C.; Cánovas, M.F.; Osorio, I.R. Polyolefin fiber-reinforced concrete enhanced with steel-hooked fibers in low proportions. Mater. Des. 2014, 60, 57-65. [CrossRef]

55. Banthia, N.; Gupta, R. Influence of polypropylene fiber geometry on plastic shrinkage cracking in concrete. Cem. Concr. Res. 2006, 36, 1263-1267. [CrossRef]

56. Hao, Y.; Cheng, L.; Hao, H.; Shahin, M.A. Enhancing fiber/matrix bonding in polypropylene fiber reinforced cementitious composites by microbially induced calcite precipitation pre-treatment. Cem. Concr. Compos. 2018, 88, 1-7. [CrossRef]

57. Li, Y.; Li, W.; Deng, D.; Wang, K.; Duan, W.H. Reinforcement effects of polyvinyl alcohol and polypropylene fibers on flexural behaviors of sulfoaluminate cement matrices. Cem. Concr. Compos. 2018, 88, 139-149. [CrossRef]

58. Afroughsabet, V.; Biolzi, L.; Monteiro, P.J.M. The effect of steel and polypropylene fibers on the chloride diffusivity and drying shrinkage of high-strength concrete. Compos. Part B Eng. 2018, 139, 84-96. [CrossRef]

59. ASTM C192/C192M-15. Standard Practice for making and Curing Concrete Test Specimens in the Laboratory; ASTM International: West Conshohocken, PA, USA, 2015.

60. ASTM C109/C109M-20b. Standard Test Method for Compressive Strength of Hydraulic Cement Mortars (Using 2-in. or [50 mm] Cube Specimens); ASTM International: West Conshohocken, PA, USA, 2015.

61. ASTM C307-18. Standard Test Method for Tensile Strength of Chemical-Resistant Mortar, Grouts, and Monolithic Surfacings; ASTM International: West Conshohocken, PA, USA, 2018.

62. Gilbert, R.I.; Bernard, E.S. Post-cracking ductility of fibre reinforced concrete linings in combined bending and compression. Tunn. Undergr. Space Technol. 2018, 76, 1-9. [CrossRef]

63. Sudhikumar, G.; Prakash, K.; Rao, M.S. Effect of aspect ratio of fibers on the strength characteristics of slurry infiltrated fibrous ferrocement. Int. J. Struct. Civ. Eng. Res. 2014, 3, 29-37.

64. Nematzadeh, M.; Fallah-Valukolaee, S. Erosion resistance of high-strength concrete containing forta-ferro fibers against sulfuric acid attack with an optimum design. Constr. Build. Mater. 2017, 154, 675-686. [CrossRef] 